nature of the case was certain, it appeared to me that the hydatid was situated in the lung immediately beneath the pleura, that it had given rise to acute pleurisy a few days before admission, and that there had been a small localised empyema, which we struck with the hypodermic syringe on the first occasion. It is not common to meet with two separate hydatid cysts in the lung; hence the idea that there were two cysts, one of which had suppurated, does not appear nearly so probable as the view I have taken.

I may add that I was much struck by the amount of muco purulent sputum, and in a reported case some months ago I noticed this also was mentioned, but without any importance being attached to it. It is possible it may be of diagnostic value, though I find no reference to its frequency. Full.

\section{THE ARSENIO-FERRIC WATER OF LEVICO.}

By W. Wynn Westcot', M.B. Lond., JOINT AUTHOR OF THE "EXTRA PHARMACOP(LIA."

TaE district and town of Levico, situated in the Tyrol, near Trient, have a rising reputation as health resorts for invalids, and the adjacent mountain side has two springs which have long been known to possess valuable curative properties. Recent analysis has shown that the water of both of them is strongly ferruginous, and also contains an important proportion of arsenic; the mild water contains eight grains of iron per pint, and $\frac{1}{12}$ th of a grain of arsenic, while the strong contains thirty-four grains of iron and one-twelfth of a grain of arsenic per pint. It becomes at once apparent, then, that we possess in these waters valuable medicinal agents. The waters are clear and colourless, and are not unpleasant to take: they command a very large distribution in Austria, Germany, and Russia, and have very recently been introduced into England. The physicians of the Continent have expressed themselves very strongly upon the merits of Levico water as an luxmatinic tonic and alterative, and it is extensively used both in hospitals and in private practice. I have now tried the waters, especially the mild, in a considerable number of cases, and several medical friends have reported to me their own experience. Levico water is extremely susceptible of assimilation; it agrees with almost every stomach if given in doses of one or two tablespoonfuls after meals three times a day. I have not met with any cases in which it disordered the stomach or otherwise upset the patient. A little water, or lieer, or wine and water may be taken after it; even coffee appears to be suitable. Speaking generally, I should recommend Levico water to be tried in cases of simple anæemia, chlorosis, general debility, and chronic skin diseases, pisoriasis especially. In the ansemic states produced by exhausting discharges, scrofulous abscesses, uterine hæmorI hages, leucorrhoea, \&c., I have observed a marked effect. The waters are imported in bottles containing half a pint, tweaty doses of one tablespoonful each, so that they are not expensive medicines. There is no other natural water containing both iron in full doses and arsenic, for La Bourboule, which has been notable as an arsenical water, contains no iron, and Royat has only a trace of either constituent.

Camden road, $N$.

\section{A PURPUPTC RASH IN INFLUENZA.}

\section{BY C. A. Locke, M.R.C.S., L.R.C.P.L.}

VARIOUs rashes have been described in connexion with the present epidemic of influenza, but I have seen no mention of anything approaching the purpuric type. The following are short notes of three cases which have lately come under my notice.

CASE 1.-H. D_-, aged twenty-six, a railway porter, a deticate looking man, but with no organic disease. Illness commenced on Nov. 24th, 1889, with shivering pains in the lack and limbs and across the eyes. He continued at work, and on the evening of the $25 \mathrm{th}$ he had to walk a distance of ten miles. He was very tired, and his legs, especially the right leg, ached severely. While undressing that night he noticed some spots on his leg, for which he sought advice on the $26 \mathrm{th}$. Down the front of the right leg there were five irregular spots varying in size from a shilling to a threepennypiece, as well as numerous smaller ones, of a dark slate colour, level with the surrounding skin, not scaly, and not disappearing on pressure. The spots faded in a few days, and a fresh crop appeared on Dec. 7 th, which in due course also disappeared. The patient was greatly prostrated, and did not return to work until Dec. 27 th, the right leg remaining weak some time after the other limbs had recovered their usual strength.

CASE 2.-A. P_, aged forty-two, cullier, a big healthy man; seen Jan. 13th. Had the usual infiuenza symptoms, and on the right forearm one typical spot of purpura about the size of a sixpence, which had appeared on the third day of the illness. He volunteered the statement that he had "jarred" his arm in an ineffectual attempt to strike a fellow-workman the day before he was taken ill. He had also been much worried about his domestic arrangements for some weeks previously.

CASE 3.-H. T-, aged eight; seen Jan. 4th, 1890. A pale, weak, little boy, with a mitral murmur at the apex. The child had had " a bad cold," with back pain and frontal headache for two days. When washing him on the third day his mother noticed a rash over the abdomen and chest. On examination the rash proved to be purpuric, the largest spots being the size of a shirt button. The spots faded quickly, being all gone in five days.

I also remember seeing a case of purpura at University College Hospital three or four years ago, where the patient had a severe " cold," which was possibly a sporadic case of influenza. These three cases were nnmistakably influenza, and the rash was as unmistakably purpuric. The rash may belong to the class of symptomatic purpura that is sometimes associated with the acute specifics, and in the case of the child the cause may have been the faulty heart. In Case 1, the fact that the right leg was the most painful before the rash, and remained weak the longest, may perhaps point to the strain put on the leg by the patient's long walk as a cause, while well in the depressing course of the disease. In Case 2 the nervous depression might count as a factor in the etiology as well as the "jarring" of the arm.

Rotherham.

\section{A NEW OPERATION FOR THE RELIEF OF} ENTROPION OF THE UPPER EYELID. ${ }^{1}$

By Thomas Evaxs, M.R.C.S.,

OPHTHALMIC SURGEON TO THE SYDNEY MOSPITIL, R.S.W.

THE various operations designed for the relief of distichiasis and entropion of the upper eyelid may be classified as follows: first, those in which the whole or a part of the cilia are removed; secondly, those in which the row of cilia is transplanted and a portion of the skin of the lid sacrificed ; thirdly, those in which the cilia and a bridge of skin taken from above them are made to exchange positions.

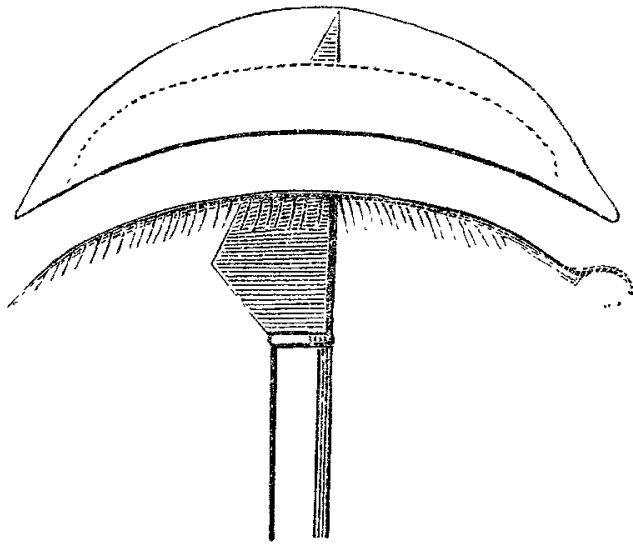

Position of knife when uniting the two incisions in the cartilage. The dotted line shows the upper edge of the separated wedge of tissue.

To the second class belong the operations of von Arlt and von Graefe; to the third those of Dianoux, Watson, Junge, and many others. The method I am about to describe cannot be placed in any of these classes. The cilia are not transplanted, but the direction of their growth is altered. No skin need be sacrificed unless the operator pleases, and a mechanical obstacle consisting of cartilage prevents the return of the cilia to their abnormal position. It is simple and effective, it never shortens the lid or interferes with the folds of skin, so necessary from a cosmetic point of view, and a month after, save in a faint linear cicatrix, and

A portion of a paper read at a meeting of the Medical Section of the Royal Society of New South Wales, on Dec. 20th, 1889. 